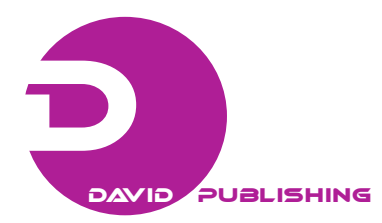

\title{
Construction and Characterization of Dye-Sensitized Solar Cells
}

Pablo César Carbo Vela, Enrique Martínez Peña, Juan López Hernández, Eddie Nahúm Armendáriz Mireles, José Amparo Rodríguez García and Enrique Rocha Rangel

Polytechnic University of Victory, Victoria City, Tamaulipas 87138, México

Received: June 24, 2013 / Accepted: July19, 2013 / Published: August 25, 2013.

\begin{abstract}
This work describes the development of solar cells manufactured with different natural dyes, with the purpose to determine their photoelectrochemical properties, employing for that virtual instrumentation. Data acquisitions and statistical process of the same, are realized through graphical programming software. The system has facilities for measurements, acquisitions and to see permanently in the computer display, information about the performance of the solar cells, as well as environmental parameters such as; temperature and the I-V characteristic curve of the solar cell. This monitoring system pretends to be part of a permanent station for monitoring variables of the manufactured solar cells.
\end{abstract}

Key words: DSCC, solar cells, dye-sensitized, photoelectrochemical properties, virtual instrumentation.

\section{Introdution}

Dye-sensitized solar cell (DSSC), are a third generation solar cells that can be referenced in literature as DSSC or Grätzel type, in agreement with its inventor and main promoter. These cells have economic potential, due the low price of the row materials and the used labor necessary for their manufacturing, in comparison with the traditionally solar cells silicon-based made [1]. For the reason that these cells based their function principle in both; light abortion process and transfer of electrons, which are performed separately, their manufacturing costs are not expensive [2]. On the other hand, because their processes mimic natural photosynthesis realized by green plants, is that since its invention, it has been growing interest in the scientific community, world around [3].

The characterization of solar cells was carried out on a laboratory scale and in real conditions outdoors, and both; on used materials for their, as in their

Corresponding author: Enrique Rocha Rangel, Ph.D., professor, research fields: production and characterization of advanced materials. E-mail: erochar@upv.edu.mx. photoelectrochemical properties. One of the means for the characterization of solar cells, is through the use of software for both; data acquisition of the most important parameters of solar cells, as well as to display the data acquired by the NI-LabVIEW Platform. Systems automatic data acquisition (DAQ), various tasks running simultaneously; monitoring the operation of a system, the control operation thereof, etc.. Its application in photovoltaic conversion systems, allows information to be used for assessing the efficiency of a solar cell for long periods and to optimize mainly on reliability [4].

\section{Experiments}

This section describes the construction of a dye-sensitized solar cell constituted by two glasses that work as electrodes; in the surface of the glasses it is deposited a graphite-based thin film to make them conductors. The KI/I redox par dissolved in ethylene-glycol is used as a conduction medium of electrons, natural dyes are used as absorbent of solar energy and finally nanometric- $\mathrm{TiO}_{2}$ is employed as a medium where dyes are anchored. During the study it 
first was tested photosynthetic pigments based on a molecule called anthocyanin (which is found in some fruits as blackberries and beets, or flowers as hibiscus), to find sensitizers showing performance in photocurrent and conversion efficiency. The Fig. 1 shows the schematic of the cell.

The DSSC solar cell was tested under real conditions in the following two ways: (a) it was tested in the shade; and (b) it was tested under light from the sun. The experiment was developed that way in order to determine the influence of the solar light was in the processes of light absorption and electron transfer into the cell. Additionally, it was used to show how the photosynthesis is imitated.

Another experiment, involved the testing of the DSSC solar cell using artificial light produced by a halogen lamp. The cell was tested in controlled conditions in order to determine its typical curve as reported in Ref. [5]. Fig. 2 shows the connections used to determine the I-V curve.

Once constructed cell, proceeded to make the connections due to observe the photoelectrochemical characteristics such as: open circuit voltage (Voc), short circuit current (Isc) and power (Pm).

Based on logging data with respect to current and voltage, it proceeded to make connections as already shown in Fig. 2. Then increased resistance values gradually by means of a potentiometer $500 \mathrm{ohms}$.

For monitoring of solar cells manufactured with different dyes, gathered the following materials, tools and equipment: Conductor glasses ITO Rs $<10 \Omega$ (Delta Technologies Limited, USA), Electrolyte potassium iodide-iodine (KI) dissolved in ethylene glycol, Titanium dioxide $\left(\mathrm{TiO}_{2}\right.$ Degussa $\left.\mathrm{P} 25<1 \mu \mathrm{m}\right)$, Graphite powder, variable resistor (potentiometer) 500 ohms, 1 digital multimeter, Natural dyes (blackberry, hibiscus and beet), DAQ card (USB-6008, National Instruments), Computer, Temperature sensor (NI USB-TC01), Termopar "J" type, Artificial light source (halogen lamp, 100 watts), Heating source (Heat gun), Nitric acid (10 $\mathrm{mL}$ in deionized water).

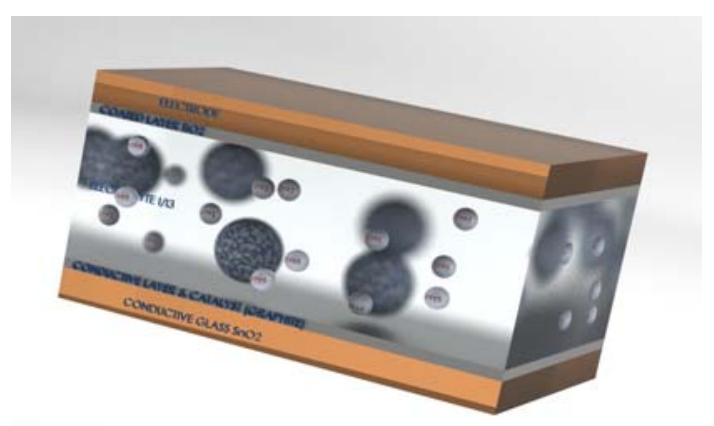

Fig. 1 Schematic of a constructed dye-sensitized solar cell.

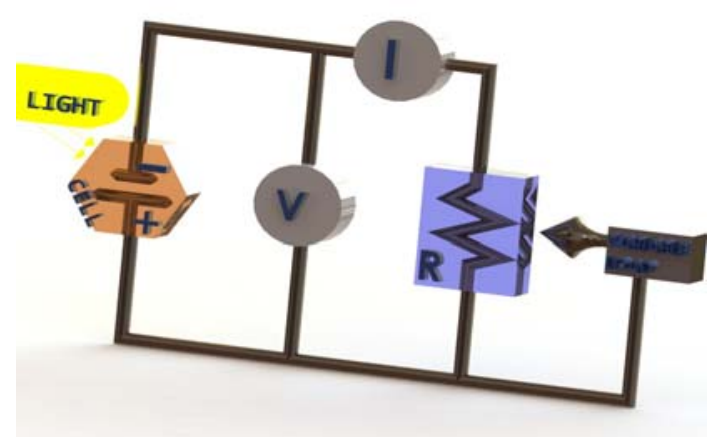

Fig. 2 Experimental setup for measuring the current-voltage (I-V) characteristics.

The goal is to characterize electrically each cell constructed with different dye, to determine the parameters for evaluating the efficiency of the cell, and in this way, start with monitoring of the cells through a data acquisition system using NI-LabVIEW platform. The light sources used were both; based artificial halogen light, as based natural sunlight.

The tests were made with artificial light indoors in controlled conditions and daylight tests were done outdoors in a partly cloudy day with an average temperature of $25{ }^{\circ} \mathrm{C}$, in Victory City, Tamaulipas, Mexico, which is in a location between $23^{\circ} 59^{\prime}$ and $23^{\circ} 24^{\prime}$ north latitude and $98^{\circ} 55^{\prime}-99^{\circ} 26^{\prime}$ west longitude, at 2:50 P.M. March 25, 2013. Sampling consisted of 360 shots at 0.5 seconds per sample for a time of 3 min. In Figs. 3 and 4 show the images of the block diagram and control panel with natural light source, respectively. In Fig. 4, the yellow curve corresponds to the signal of blackberry, the red curve to hibiscus signal and the green curve to beet signal. 


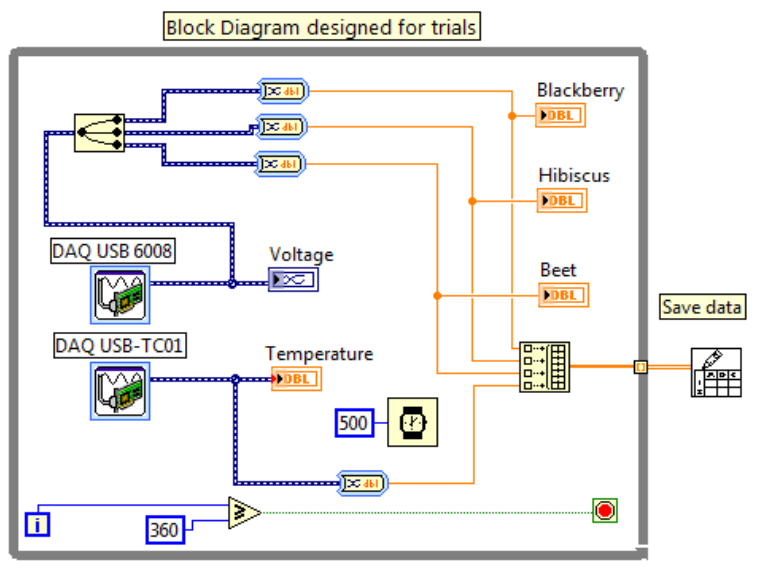

Fig. 3 Block diagram designed for trials.

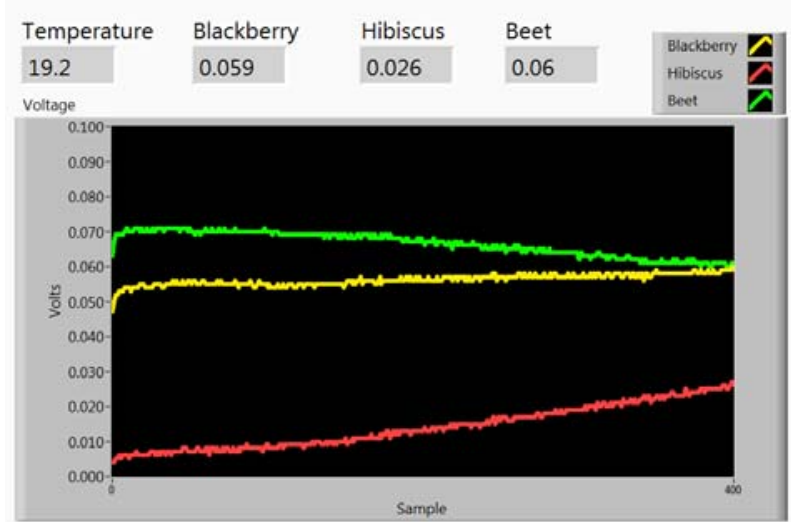

Fig. 4 Measurements with the control panel using natural light source.

\section{Experimental Results}

The graph in Fig. 5, shows the curves of current vs. voltage (I-V) and powder corresponding to DSCC constructed cell. Here it can see the short circuit current Isc and open circuit voltage Voc. During the experiment, 14 measurements were performed regulated with a potentiometer of 500 ohms, the cell was illuminated with artificial light based on halogen light, which reproduces radiation conditions similar to sunlight [6]. The I-V curve from figure 5 corresponds with the reported in Ref. [7]. The maximum achievable power levels can be seen around 0.17 volts.

In order to make a comparative analysis of anthocyanin present in some plants and fruits, they were constructed and characterized sensitized solar cells made with natural dyes such as; blackberry, hibiscus flower and beet. Thus voltage measurements were made on each and evaluating them with respect to the temperature under a artificial light source.

Fig. 6 shows the tendency of the dyes to decrease their efficiency levels as the exposure time increases and especially when the cell temperature increases. This decrease in efficiency is higher in the cell constructed with blackberry dye, a little light in the cell made with hibiscus dye and almost imperceptible in the cell constructed with beet dye. However, even with the strong decrease in voltage in the cell made with blackberry, its efficiency levels are well above the levels of efficiency of cells made with hibiscus or beets. Indicating that the anthocyanin present in this fruit has better characteristics to absorb light energy compared with anthocyanin present in hibiscus and beets.

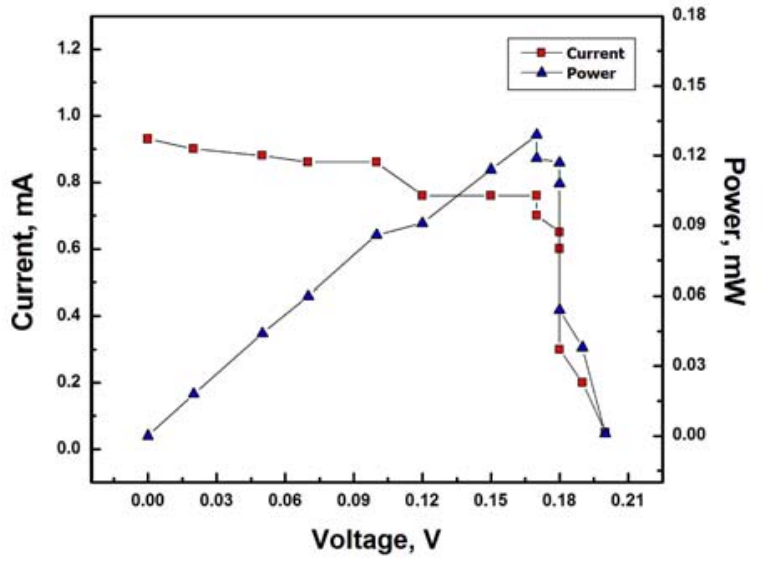

Fig. 5 Raph of the IV curve of the DSSC cell with artificial light.

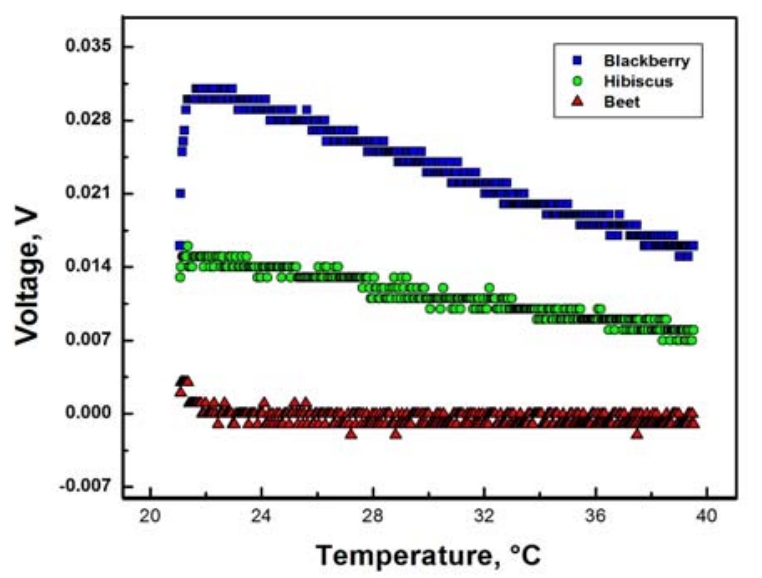

Fig. 6 Raph showing the voltages generated under artificil light by the cells made with different dyes. 


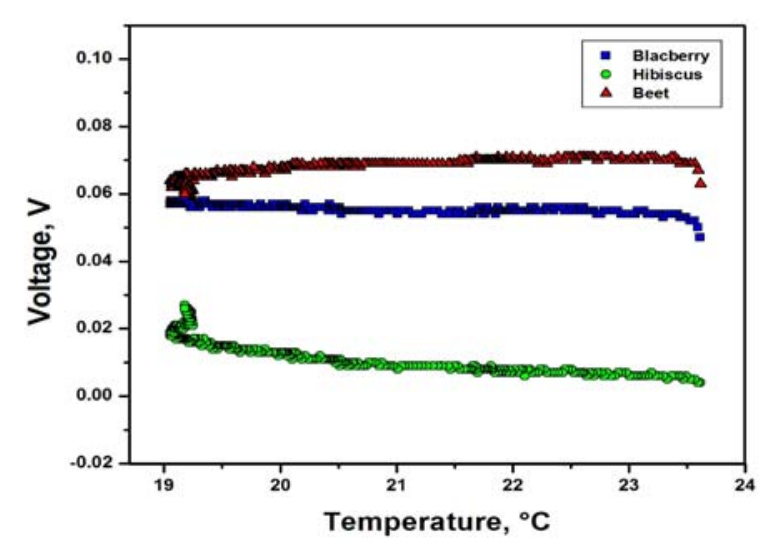

Fig. 7 Raph showing the voltages generated under natural light by the cells made with different dyes.

The decrease in cell efficiency is due to the heat generated by the halogen light source of 100 watt, decomposing the dye. Though, there are factors that determine chemical anthocyanin stability during processing and storage, when it is subjected to temperatures above $70^{\circ} \mathrm{C}$ as it is reported in Ref. [8].

Also it was performed a characterization of the cells using a natural light source. The resulting graph is shown in Fig. 7 where it can be seen that did not change significantly the levels of efficiency and stability when it is used sunlight. However also it is seen in this graph a very similar behavior in terms of energy absorption efficiency for cells manufactured with beet and blackberry dyes, being here a little better the efficiency in the cell made with beets. Also, energy absorption efficiency in these two cells, does not diminish with time or temperature. Furthermore, the cell made with hibiscus dye has low energy absorption efficiency, in addition this decreases further with increasing temperature.

\section{Conclusions}

It was performed the characterization of solar cells sensitized with different natural dyes by monitoring them using NI-LabVIEW platform. Based on the results obtained during the evaluation of the photoelectrochemical properties, it can conclude that
DSSC type solar cells can compete with the commercial type cells made with standard processes. It was observed that such cells have a more stable response in rooms with natural light, considering that this light source provides a wider range of energy wavelengths thus obtains a higher excitation of the particles in the anthocyanin. The I-V curve shows the expected monotonous behavior, with peak power up to around 0.17 volts. The use of virtual instrumentation helped in permanent monitoring in real time of the cells thus able to obtain the information necessary to make improvements in the design and construction of the same.

Of the dyes studied, which present greater stability and efficiency in terms of energy absorption was blackberry.

\section{References}

[1] B.O. Regan, M. Grätzel, A low-cost, high efficiency solar cell based on dye sensitized colloidal $\mathrm{TiO}_{2}$ films, Nature 335 (1991) 737-740.

[2] N. Cherepy, G.P. Smestad, M. Grätzel, J. Zhang, Ultrafast electron injection; Implications for a photoelectrochemical cell utilizing an anthocyanin dye-sensitized $\mathrm{TiO}_{2}$ nanocrystalline electrode, J. Phys. Chem. B.101 (1997) 9342-9347.

[3] G.P. Smestad, M. Grätzel, Demonstrating electron transfer and nanotechnology: A natural dye-sensitized nanocrystalline energy converter, J. Chem. Educ. 75 (1998) 752-755.

[4] G. Blaesser, PV system measurements and monitoring the European experience, Solar Energy Materials and Solar Cells 47 (1997) 167-176.

[5] N. Sekar, V. Gehot, Metal complex dyes for dye-sensitized solar cells: Recent developments, India: Institute of Chemical Technology (2010) 819-831.

[6] C. Abalos, Behavior of the intensity of light of halogen lamps and LEDs through the composite, Dentum 5 (2005) 102-106.

[7] K. Zweibel, Thin-film photovoltaic cells, American Scientist 81 (1993) 362-369.

[8] B. Cevallos-Casals, L. Cisneros-Zeballos, Stability of anthocyanin based aqueous extract of andean purple corn and red fleshed sweet potato compared to synthetic and natural colorants, Food Chemical 86 (2004) 69-77. 